\title{
Thermodynamic Study of Adsorption of Phenol, 4-Chlorophenol, and 4-Nitrophenol on Activated Carbon Obtained from Eucalyptus Seed
}

\author{
Nelson Giovanny Rincón-Silva, ${ }^{1}$ Juan Carlos Moreno-Piraján, ${ }^{1}$ \\ and Liliana Giraldo Giraldo ${ }^{2}$ \\ ${ }^{1}$ Departamento de Química, Universidad de los Andes, Grupo de Investigación en Sólidos Porosos y Calorimetría, \\ Carrera 1A No. 18a-10, Bogotá, Colombia \\ ${ }^{2}$ Departamento de Química, Universidad Nacional de Colombia, Avenida Carrera 30 No. 45-03, Bogotá, Colombia
}

Correspondence should be addressed to Juan Carlos Moreno-Piraján; jumoreno@uniandes.edu.co

Received 29 September 2014; Accepted 29 December 2014

Academic Editor: Cengiz Soykan

Copyright (C) 2015 Nelson Giovanny Rincón-Silva et al. This is an open access article distributed under the Creative Commons Attribution License, which permits unrestricted use, distribution, and reproduction in any medium, provided the original work is properly cited.

\begin{abstract}
Activated carbons from shell eucalyptus (Eucalyptus globulus) were prepared by chemical activation through impregnation with solutions of two activators: sulfuric acid and sodium hydroxide, the surface areas for activated carbons with base were 780 and $670 \mathrm{~m}^{2} \mathrm{~g}^{-1}$ and the solids activated with acid were 150 and $80 \mathrm{~m}^{2} \mathrm{~g}^{-1}$. These were applying in adsorption of priority pollutants: phenol, 4-nitrophenol, and 4-chlorophenol from aqueous solution. Activated carbon with the highest adsorption capacity has values of 2.12, 2.57, and 3.89 on phenol, 4-nitrophenol, and 4-chlorophenol, respectively, and was activated with base. In general, all carbons adsorption capacity was given in the following order: 4-chlorophenol $>4$-nitrophenol $>$ phenol. Adsorption isotherms of phenols on activated carbons were fitted to the Langmuir, Freundlich, and Dubinin-Radusckevisch-Kanager models, finding great association between them and experimental data. A thermodynamic study was performed, the exothermic nature and spontaneous nature of the adsorption process were confirmed, and the favorability of adsorption on activated carbons with $\mathrm{NaOH}$ was confirmed by energy relations and concluded that the adsorption process of phenolic compounds from the activated carbon obtained is physical. The $\mathrm{pH}$ of solutions and $\mathrm{pH}$ at point of zero charge of the solid play an important role in the adsorption process.
\end{abstract}

\section{Introduction}

Utilization of lignocellulosic waste to produce activated carbon is an important approach in air pollution control strategy. Lignocellulosic waste can be considered as abundant agricultural wastes. Converting these wastes into value added product such as activated carbon could solve environmental problems such as accumulation of agricultural waste, air pollution, and water pollution. In addition, using activated carbon from lignocellulosic biomass instead of fossil sources such as coal will reduce global warming effects. Therefore, the circulation of carbon between atmosphere and pollutant removal process is merely a carbon-neutral cycle. Apart from being effective in pollutant removal, lignocellulosic activated carbon is relatively economical, because it is sourced from agricultural sector wastes and is abundantly available [1].

Lignocellulosic waste derived from agricultural byproducts has proven to be a promising type of raw material for producing activated carbon, especially due to its availability at a low price. A number of studies on various applications of lignocellulosic materials as activated carbon sorbents have been published by various researchers [1-4]. Lignocellulosic waste generally can be classified into three different components, which are cellulose, hemicellulose, and lignin. Among the three, lignin has been identified as the main component in lignocellulosic waste responsible for the adsorption process [1-3]. Lignin based biomass is the most abundant renewable carbon resource on earth after cellulose, with a worldwide 
production of 40-50 million tons per year $[1,2]$. Due to the rich carbon content of lignin, lignocellulosic waste is a good option to be used as precursor for producing activated carbon $[1,5,6]$. Activated carbon with high adsorption capacity can be produced from numerous sources of lignocellulosic [1, 713] and hazelnut shell [13-15].

Activated carbon derived from lignocellulosic waste is widely used for pollutant removal. Various industrial sectors use lignocellulosic activated carbon in operations such as chemical processes, petroleum refining, wastewater treatment, air pollution treatment, and volatile organic compounds (VOC) adsorption [1, 13-16]. In addition, activated carbon provides an effective mean for gas phase applications, such as for separation, deodorization, purification, storage, and catalysis [1]. Activated carbon is a well-known adsorbent due to its unique and versatile properties that allow the accessible of gas/liquid into internal pore surface and high degree of surface reactivity $[1,13]$. The important properties of activated carbon are that it is comprised of high surface area, developed microporous structure, and favorable pore size $[1,12-16]$.

Phenolic derivatives are widely used as intermediates in the synthesis of plastics, dyes, pesticides, and insecticides, among others [1]. Their presence, increasingly common in drinking water and municipal and industrial waste, represents a serious threat to the environment and human health. Most of these compounds are carcinogenic and highly toxic. The constant presence at low concentrations causes unpleasant taste and smell to water bodies, having negative effects on different biological processes $[17,18]$.

These organic compounds can be removed from water using different processes. Adsorption by activated carbons (ACs) is highlighted as one of the technologies available to treat contaminated water, because this process removes not only phenols but also other organic and inorganic compounds usually found in wastewater, making it a complementary system of treatment $[18,19]$.

The use of activated carbon as adsorbent of contaminants in water is due to textural and chemical properties, and also the raw material and the method of preparation, which can be modified by physical and chemical treatments to improve the adsorptive properties $[19,20]$. The most common materials used for the preparation of activated carbon are from lignocellulosic and mineral origin, including wood, peat, petroleum, and coke. The adsorption capacity of activated carbon in solution depends on various factors such as the texture, surface chemistry, and temperature and adsorbate characteristics like molecular weight, polarity, $\mathrm{pK}_{\mathrm{a}}$, molecular size, and functional groups. Another important factor is the solution condition such as $\mathrm{pH}$, adsorbate concentration, and presence of other adsorbates [21].

The adsorption in liquid phase is a complex process that requires experimental methods capable of characterizing the surface of the solid in terms of surface area, porosity, nature, and energy of adsorption sites; the technique used to study the phenol-activated carbon adsorption system on aqueous solution is the building of the adsorption isotherm that can be complemented with other techniques such as immersion calorimetric and adsorption thermodynamics.
The lignocellulosic residues are the main source of materials to the preparation of ACs, due to its advantages over other precursors including low cost, easy availability, and easy handling. However, it is necessary to modify the properties of activated carbons in order to improve the adsorption capacity of these solids [21].

An alternative method conventional of preparation of activated carbons is the carbonization method is the chemical treatment with concentrated sulphuric acid $\left(\mathrm{H}_{2} \mathrm{SO}_{4}\right)^{\bullet} \mathrm{H}_{2} \mathrm{SO}_{4}$, which is a powerful dehydrating agent, can react with organic compounds (i.e., carbohydrates and other organic substances) removing water and degrading the organic precursor to elemental carbon $\left(\mathrm{C} n \mathrm{H}_{2 n} \mathrm{O}_{n}+\mathrm{H}_{2} \mathrm{SO}_{4} \rightarrow n \mathrm{C}+\right.$ $\mathrm{H}_{2} \mathrm{SO}_{4} \cdot n \mathrm{H}_{2} \mathrm{O}$ ) [22-25]. In the specific case of lignocellulosic materials, such as wood $\left(\mathrm{CH}_{1.44} \mathrm{O}_{0.66}\right)$ [22] or cherry stones $\left(\mathrm{CH}_{1.52} \mathrm{O}_{0.62} \mathrm{~N}_{0.006}\right)[22,25], \mathrm{H}_{2} \mathrm{SO}_{4}$ can promote a partial degradation of the cellulose and hemicellulose fractions, mainly via dehydration reactions, leaving a modified lignin residue [26-29]. In addition, $\mathrm{H}_{2} \mathrm{SO}_{4}$ is a mineral acid that can react with inorganic constituents of lignocellulosic materials originating their dissolution [27-29]. In fact, $\mathrm{H}_{2} \mathrm{SO}_{4}$ has been frequently used as cleaning and deashing agent of $\mathrm{AC}$ precursors [29]. Thus, the use of $\mathrm{H}_{2} \mathrm{SO}_{4}$ for carbonisation purposes may be advantageous as far as process cost $\left(\mathrm{H}_{2} \mathrm{SO}_{4}\right.$ is a little expensive chemical) and chemical composition of $\mathrm{AC}$ is concerned. Also, it may result in the preparation of AC with different porous structures.

The present work studied the adsorption of priority pollutants: phenol, 4-nitrophenol, and 4-chlorophenol on activated carbon obtained from eucalyptus seed husk synthesized by chemical activation, using two activators $\mathrm{NaOH}$ and $\mathrm{H}_{2} \mathrm{SO}_{4}$. Furthermore, the adsorption process was evaluated in thermodynamic terms.

\section{Materials and Methods}

2.1. Preparation of Activated Carbon. Eucalyptus peel was crushed and sieved to a particle size of $50 \mu \mathrm{m}$. The precursor was impregnated with solutions of $\mathrm{NaOH}$ and $\mathrm{H}_{2} \mathrm{SO}_{4}$ (1 gram of precursor per $2 \mathrm{~mL}$ of solution) for 10 hours at $20^{\circ} \mathrm{C}$. After drying at $40^{\circ} \mathrm{C}$ for 2 hours, this material was carbonized in a horizontal oven at a linear heating rate of $10^{\circ} \mathrm{C} \mathrm{min}^{-1}$ up to a temperature of 550 or $750^{\circ} \mathrm{C}$, depending on the activation with acid or base, the temperature maximum is for the use of basic remaining in this temperature for 2 hours with flow of $\mathrm{N}_{2}$ at $100 \mathrm{~mL} \mathrm{~min}^{-1}$. Finally, the ACs were washed with $0.1 \mathrm{M}$ hydrochloric acid and distilled water to neutral $\mathrm{pH}$ to remove traces of the chemical agent used in the impregnation.

Solutions of 15 and $30 \% \mathrm{H}_{2} \mathrm{SO}_{4}$ and $\mathrm{NaOH}$ were used to prepare activated carbons which are labeled as AC, followed by letters A (for AC treatment with acid) and B (for AC treatment with base) and finally with a number that represents the concentration of acid or base: ACA15, ACA30, ACB15, and ACB30.

\subsection{Characterization}

2.2.1. Apparent Surface Area and Porosity. $100 \mathrm{mg}$ of ACs is desorbed for $3 \mathrm{~h}$ at $250^{\circ} \mathrm{C}$. Adsorption isotherms of nitrogen 
TABLE 1: Textural and acid-base properties of ACs.

\begin{tabular}{lcccccccr}
\hline ACs & $S_{\text {B.E.T. }}\left(\mathrm{m}^{2} \mathrm{~g}^{-1}\right)$ & $\begin{array}{c}V_{\mu \text { poro }} \\
\left(\mathrm{cm}^{3} \mathrm{~g}^{-1}\right)\end{array}$ & $\begin{array}{c}V_{\text {mesopore }} \\
\left(\mathrm{cm}^{3} \mathrm{~g}^{-1}\right)\end{array}$ & $\begin{array}{c}V_{\text {total }} \\
\left(\mathrm{cm}^{3} \mathrm{~g}^{-1}\right)\end{array}$ & $\begin{array}{c}E_{0} \\
\left(\mathrm{~kJ} \mathrm{~mol}^{-1}\right)\end{array}$ & $\begin{array}{c}\text { Total acidity } \\
\left(\mathrm{meq} \mathrm{g}^{-1}\right)\end{array}$ & $\begin{array}{c}\text { Total basicity } \\
\left(\mathrm{meq} \mathrm{g}^{-1}\right)\end{array}$ & $\mathrm{pH}_{\text {PZC }}$ \\
\hline ACA15 & 150 & 0.084 & 0.511 & 0.595 & 6.920 & 0.116 & 0.118 & 6.5 \\
ACA30 & 80 & 0.005 & 0.015 & 0.020 & 2.301 & 0.162 & 0.108 & 6.7 \\
ACB15 & 780 & 0.289 & 0.870 & 1.159 & 14.582 & 0.104 & 0.462 & 7.8 \\
ACB30 & 670 & 0.283 & 0.166 & 0.449 & 16.055 & 0.116 & 0.700 & 8.5 \\
\hline
\end{tabular}

were taken at $77 \mathrm{~K}$, on a computer system Autosorb 3B, Quantachrome Co.; from this, the surface area was calculated by model B.E.T. and the micropore volume using the DubininRadushkevich model [30, 31].

2.2.2. Surface Chemistry. The selective method for determining of the total acid and basic sites on the carbon surface was employed [32] $\mathrm{pH}$ at point of zero charge $\left(\mathrm{pH}_{\mathrm{PZC}}\right)$ was determined using the titration method of mass using a $\mathrm{pH}$ meter CG840B Schott [33].

2.3. Adsorption Isotherms. The adsorption capacity of the activated carbons was evaluated using, as adsorbates, phenol, 4-chlorophenol (4-CP), and 4-nitrophenol (4-NP) on aqueous solutions at different concentrations, and the equilibrium concentration was determined by UV-VIS spectrophotometric with equipment Milton Roy Co., Spectronic Genesys SN, at a wavelength of 269,280 , and $319 \mathrm{~nm}$ for phenol, 4-CP, and 4 -NP, respectively $[17,20,34]$.

2.4. Thermodynamic Analysis. A thermodynamic study of adsorption process of phenols on ACs to estimate the feasibility of the adsorption process was performed.

The Gibbs free energy change $\left(\Delta G^{\circ}\right)$ values can discern whether a process is spontaneous or not, and negative values of $\Delta G^{\circ}$ imply a spontaneous process. The enthalpy change $\left(\Delta H^{\circ}\right)$ provides information about the exothermic nature or endothermic nature of the process and differentiate between physical and chemical adsorption processes [17, 19, 35].

The entropy change $\left(\Delta S^{\circ}\right)$ predicts the magnitude of changes in the adsorbent surface, this due to the observed changes in the reversibility, which is affected in its negative values obtained $[17,18]$.

The change in Gibbs free energy $\left(\Delta G^{\circ}\right)$ was determined using the following equation:

$$
\Delta G^{\circ}=-R T \text { In } K,
$$

where $R$ is the universal gas constant, $T$ is the temperature in Kelvin, and $K$ is equilibrium constant.

Van't Hoff equation allows obtaining values of $\Delta H^{\circ}$ and $\Delta S^{\circ}$; this equation is obtained from the free energy equation as follows:

$$
\Delta G^{\circ}=\left(\Delta H^{\circ}-T\right) \Delta S^{\circ} .
$$

Equating (1) and (2),

$$
-R T \operatorname{In} K=\left(\Delta H^{\circ}-T\right) \Delta S^{\circ} .
$$

So if In $K$ is cleared equation Van't Hoff gets [17-19]

$$
\text { In } K=\frac{\Delta S^{\circ}}{R}-\frac{\Delta H^{\circ}}{R T} .
$$

Additionally, a study of the variation of the molar free energy of adsorption process for the three adsorbates was conducted at the temperature of $20^{\circ} \mathrm{C}$.

\section{Results}

\subsection{Characterization of Activated Carbons}

3.1.1. Textural and Chemical Properties. Figure 1 shows the nitrogen adsorption isotherms for ACs, and it can be seen that these adjusted to type I isotherm according to the IUPAC classification, especially ACs with sodium hydroxide, where a greater volume adsorbed at low relative pressures is observed, characteristic of microporous solids, and the next part of the isotherm is not completely linear, indicating the presence of a larger pore size generated by the activation type [31-36].

In Table 1, the apparent surface area calculated using the BET model, the micropore volume and the characteristic energy calculated using the Dubinin-Radushkevich model, the mesopore volume, and the total pore volume are presented. The characteristics of the surface chemistry are also presented.

The results show significant differences in the textural properties of solids. The sample with greater surface area apparent was ACB15 with $780 \mathrm{~m}^{2} \mathrm{~g}^{-1}$, for ACB30 the area is $670 \mathrm{~m}^{2} \mathrm{~g}^{-1}$, despite being activated with the same impregnating agent, and the sample that activated lower concentration of the base has larger surface area because the activation at low concentration promotes the development of microporosity [12]. The ACA15 carbon has an area value of $150 \mathrm{~m}^{2} \mathrm{~g}^{-1}$ and ACA30 area was smaller with $80 \mathrm{~m}^{2} \mathrm{~g}^{-1}$, and the samples activated with base have values area up to ten times higher with respect to the acid activated. The micropore volume results obtained by the DR model show the same trend; CAB15 has the highest micropore volume with $0.29 \mathrm{~cm}^{3} \mathrm{~g}^{-1}$.

Acid-base properties of activated carbons are also presented, and ACB30 carbon has the largest concentration of basic surface groups which may be ether, chromenes or pyrones with value of $0.700 \mathrm{meqg}^{-1}$, six times higher than for the sample ACA30 containing $0.108 \mathrm{meq} \mathrm{g}^{-1}$ due to the different activating agent used; additionally, $\mathrm{pH}_{\mathrm{PZC}}$ confirms the basic behavior with values 8.5 for ACB30. 


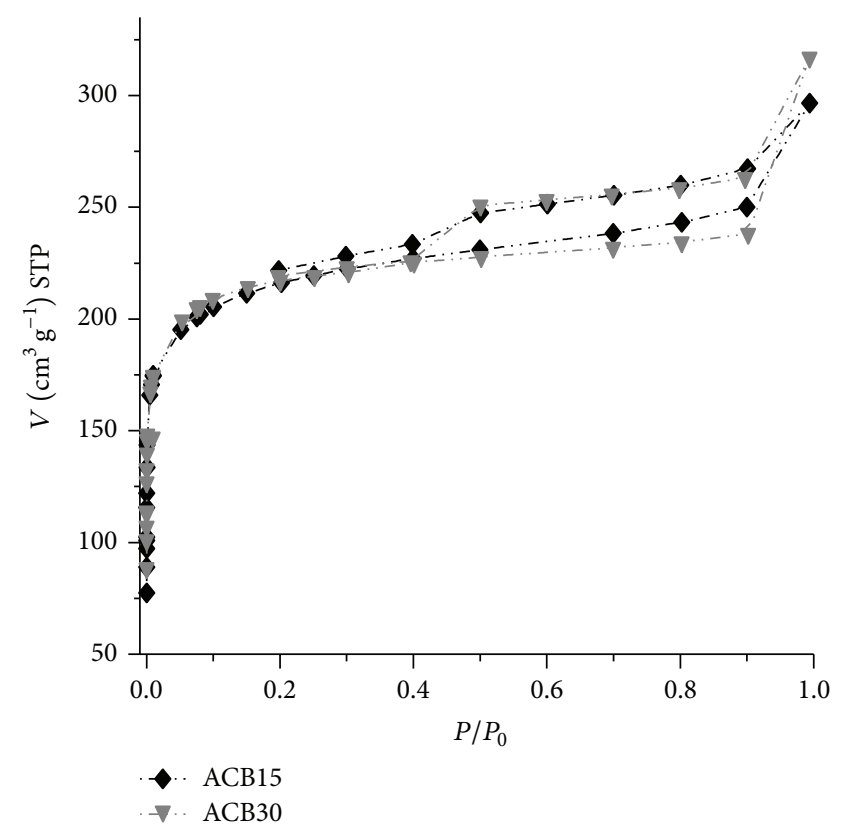

(a)

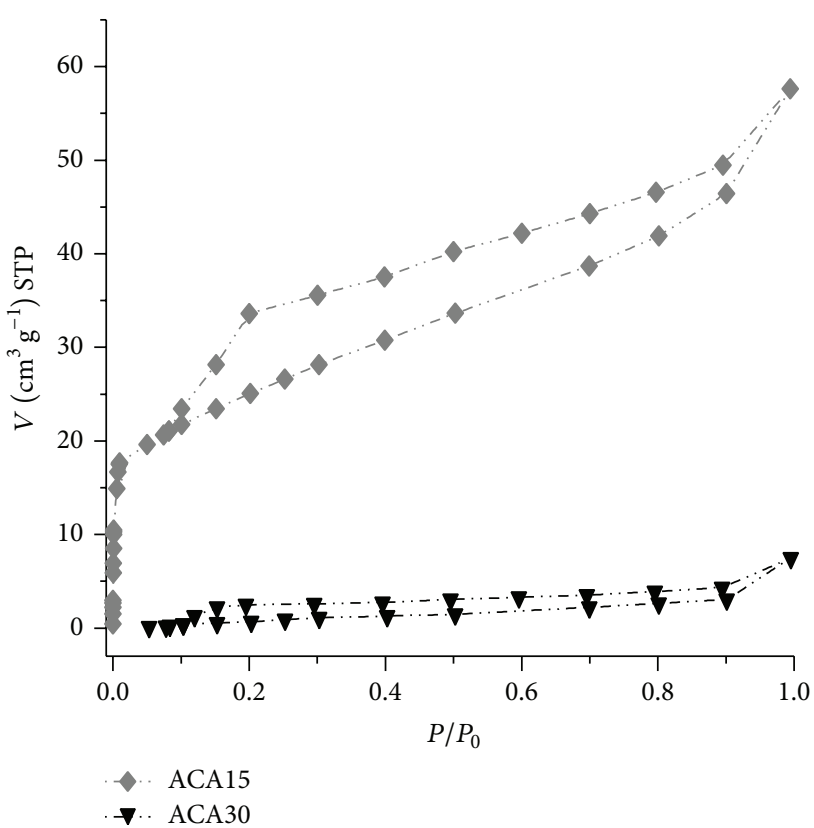

(b)

FIGURE 1: Nitrogen adsorption isotherms at $77 \mathrm{~K}$ of the ACs.

In the acid functional groups, it was found that the carbon ACA30 contains the highest concentration of these with a value of $0.162 \mathrm{meq} \mathrm{g}^{-1}$, and it is observed that ACs activated with sulfuric have low content of oxygenated groups and $\mathrm{pH}_{\mathrm{PZC}}$ tending to neutrality. Generally, samples that have low acid surface groups favor the adsorption of phenol derivatives on the surface.

3.2. Adsorption Equilibrium. The adsorption isotherms of phenols on ACs were studied at 20,30 , and $40^{\circ} \mathrm{C}$ and the results are presented in Figures 2, 3, and 4.

Figure 2(a) presents the adsorption isotherms of phenol at the three temperatures on ACs activated with acid sulfuric acid. As can be see, with increasing temperature decreases the amount of phenol adsorbed, it shows the exothermic nature of the process on the ACA15, which has greater amount of phenol retained, which is related with textural properties, isotherms exhibit Freundlich behavior. Figure 2(b) corresponds to the adsorption of phenol on ACs with sodium hydroxide, and this also prove that the adsorption process is exothermic. These isotherms are adjusted to the Langmuir model and are asymptotic to high concentrations [36-39].

ACs with base have higher adsorption capacity of phenol, with values up to approximately $2.0 \mathrm{mmol} \mathrm{g}^{-1}$, as these have the highest values in the textural properties and the content of basic surface groups is higher which favors adsorption of phenol due to the electronic interaction of $\pi$ electrons system between the solid and the solute.

The isotherms of Figures 3(a) and 3(b) represent the 4-nitrophenol adsorption, and these are adjusted to the Langmuir model behavior; again it shows that the carbons having higher adsorptivity were the activated with sodium hydroxide, and the higher adsorptivity of nitrophenol with respect to phenol is also evidenced.

Adsorption isotherms of 4-chlorophenol are shown in Figures 4(a) and 4(b); these isotherms are similar to phenol and 4-nitrophenol and behavior becomes to be asymptotic at high concentrations, and again the amount of phenolic compound adsorbed was greater at low temperatures; its differ in the adsorption capacity, increasing the amount of 4$\mathrm{CP}$ adsorbed in relation to 4-NP and phenol, and adsorption on ACs with $\mathrm{NaOH}$ was favored.

Different adjustment models were used to study the adsorption equilibrium of phenolic compounds on ACs. The used models in the fit were the Langmuir, Freundlich, and Dubinin- Radusckevisch-Kanager; these and the parameters resulting from the linearization of the experimental data are presented in Table 2.

The maximum adsorbed amount is greater for ACB30 with respect to other carbons on phenolic compounds with values of $2.13,2.57$, and $3.89 \mathrm{mmol} \mathrm{g}^{-1}$ for phenol $4-\mathrm{NP}$ and 4-CP, respectively. Moreover, the lower amount of sample retained is on ACA15, and this behavior is expected considering the textural characteristics of these carbons. The $K$ parameter also has the highest values for ACB30 with values up to $100.6 \mathrm{mmol} \mathrm{L}^{-1}$ on 4-nitrophenol adsorption.

A feature of the Langmuir model has been described for the separation factor $R_{L}$, which is defined as $R_{L}: 1 / 1+K C_{0}$ (where $C_{0}$ is the initial concentration of the adsorbate and $K$ is the constant Langmuir), and this parameter indicates the nature of the adsorption of the following way [17]:

$$
\begin{gathered}
R_{L}>1, \quad \text { (unfavorable), } \\
0<R_{L}<1, \quad \text { (unfavorable), } \\
R_{L}=0, \quad \text { (irreversible). }
\end{gathered}
$$



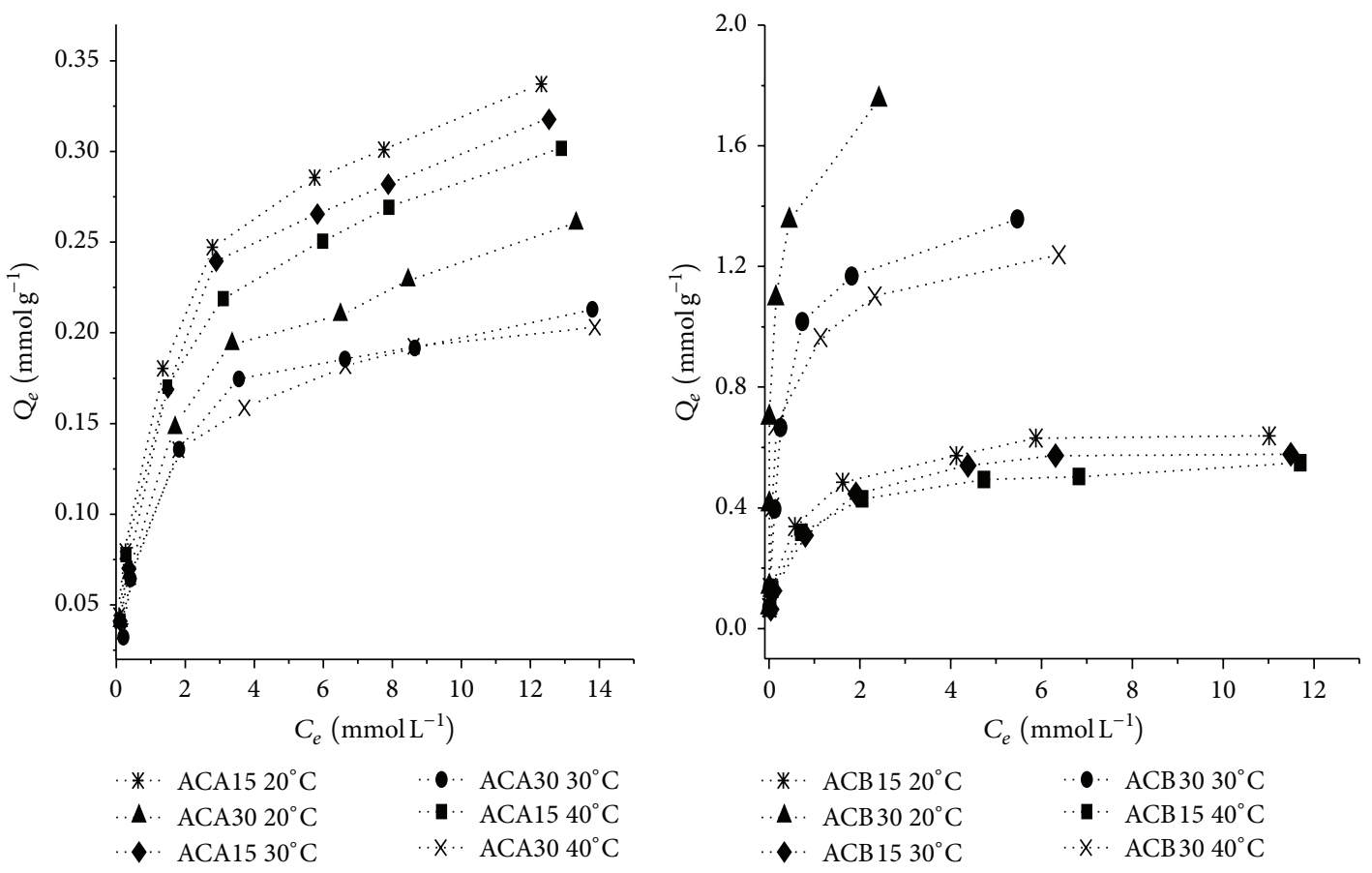

(a)

(b)

Figure 2: Adsorption isotherms of phenol on ACs evidenced.

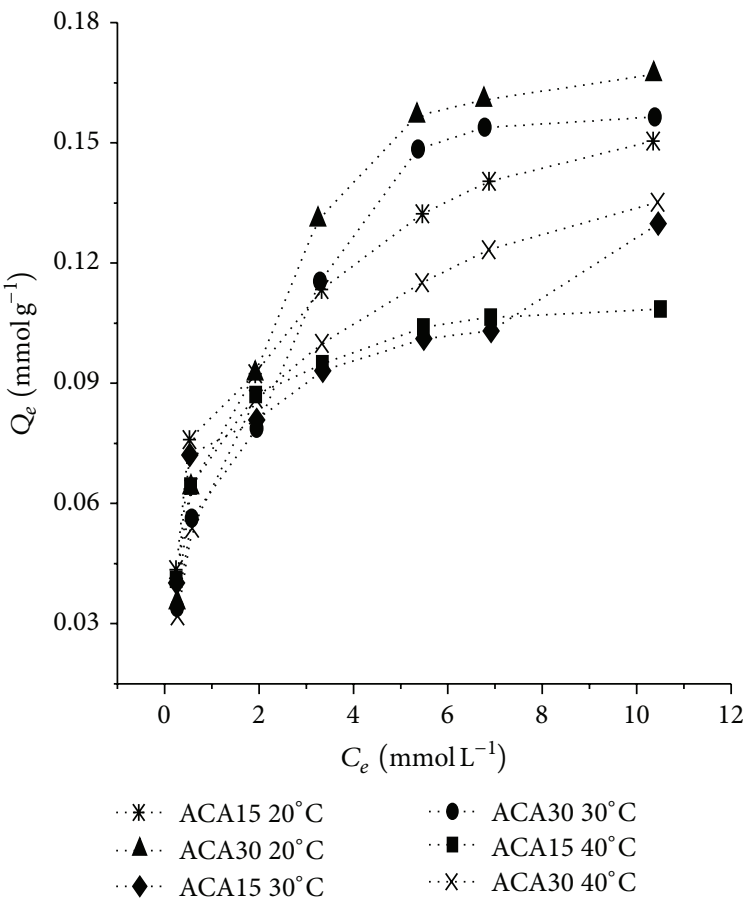

(a)

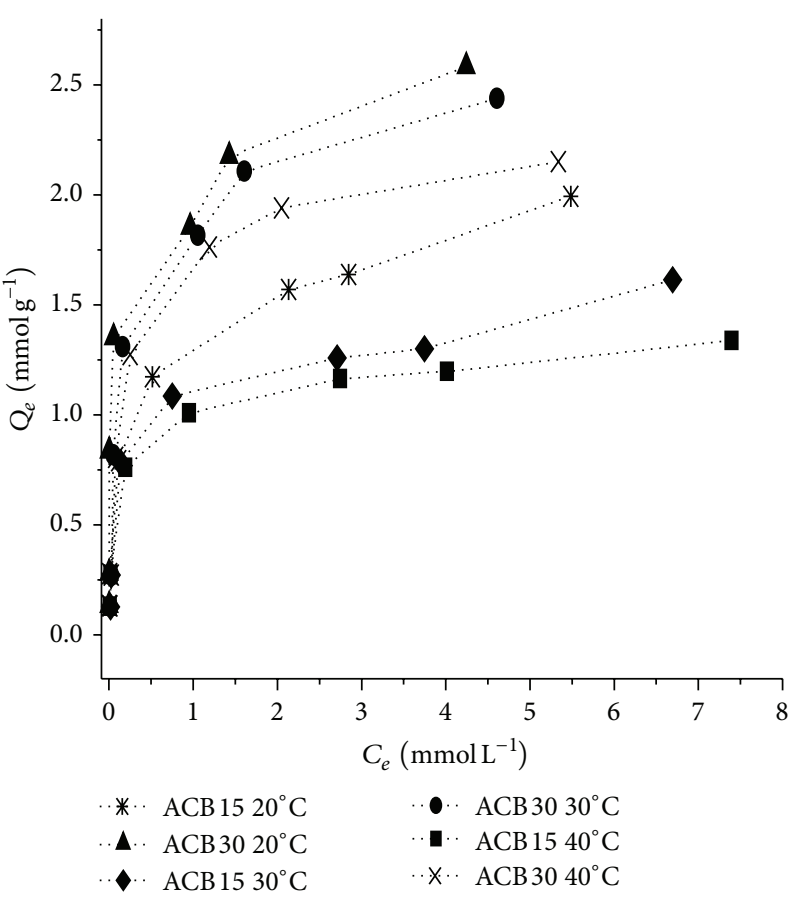

(b)

FIgURE 3: Adsorption isotherms of 4-nitrophenol on ACs. 


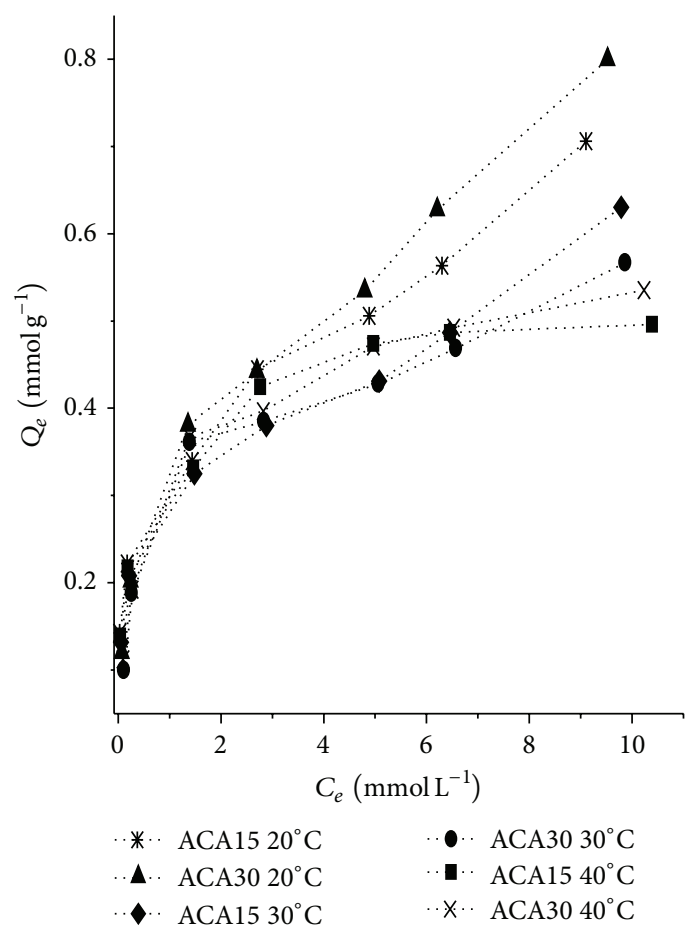

(a)

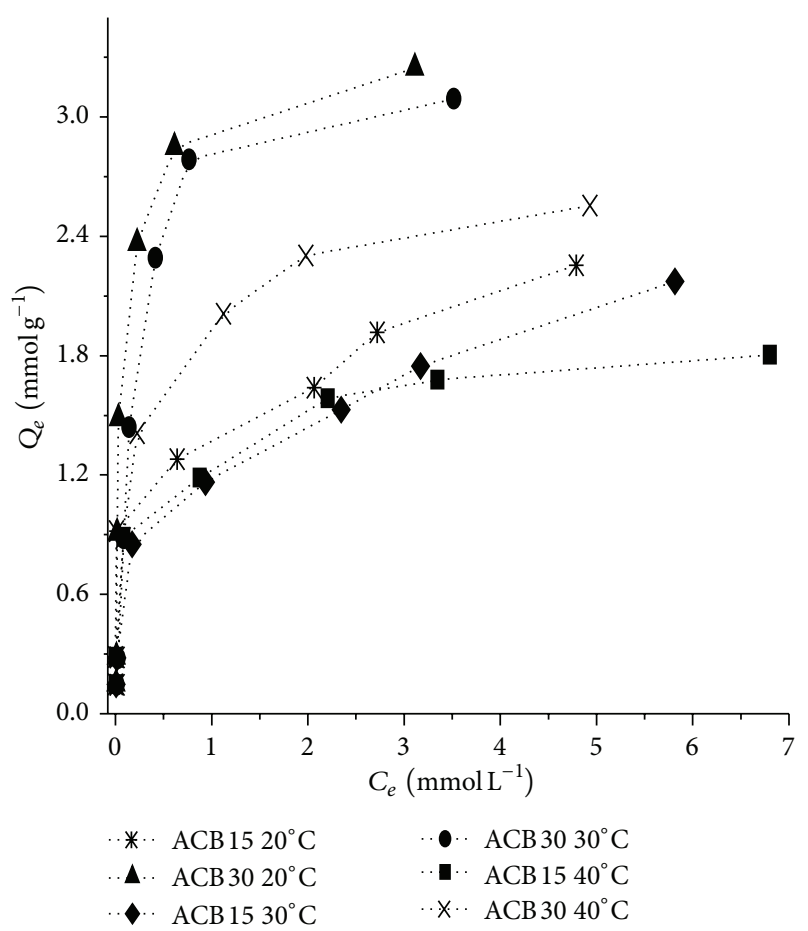

(b)

FIGURE 4: Adsorption isotherms of 4-chlorophenol on ACs.

TABLE 2: Langmuir, Freundlich, and Dubinin-Raduskevich-Kaganer models parameter for the adsorption of phenols on ACs at $20^{\circ} \mathrm{C}$.

\begin{tabular}{|c|c|c|c|c|c|c|c|c|c|c|}
\hline \multirow[b]{2}{*}{ Phenols } & \multirow[b]{2}{*}{ ACs } & \multicolumn{3}{|c|}{$Q_{e}=\left(Q_{\max }^{\text {Langmuir }} k C_{e}\right) /\left(1+k C_{e}\right)$} & \multicolumn{3}{|c|}{$\begin{array}{l}\text { Freundlich } \\
Q_{e}=k_{f}\left(C_{e}\right)^{1 / n}\end{array}$} & \multicolumn{3}{|c|}{$\begin{array}{c}\text { Dubinin-Raduskevich-Kaganer } \\
Q_{e}=Q_{m \mathrm{DRK}} \exp \left[-\left(R T \ln \left(C_{s} / C_{e}\right)\right) / E_{S}\right]^{n}\end{array}$} \\
\hline & & $\begin{array}{l}Q_{\max } \\
\mathrm{mmolg}^{-1}\end{array}$ & $\begin{array}{c}K \\
\mathrm{~L} \mathrm{mmol}^{-1}\end{array}$ & $R^{2}$ & $\begin{array}{c}k_{f} \\
\left(\left(\mathrm{mmol} \mathrm{g}^{-1}\right)\right. \\
\left.\left(\mathrm{L} \mathrm{mmol}^{-1}\right)^{1 / n}\right)\end{array}$ & $1 / n$ & $R^{2}$ & $\begin{array}{l}Q_{m \mathrm{DRK}} \\
\mathrm{mmolg}^{-1}\end{array}$ & $E_{S}$ & $R^{2}$ \\
\hline \multirow{4}{*}{ Phenol } & ACA15 & 0.313 & 0.796 & 0.98 & 1.797 & 0.442 & 0.98 & 0.331 & 19.44 & 0.97 \\
\hline & ACA30 & 0.231 & 0.773 & 0.98 & 1.645 & 0.387 & 0.97 & 0.236 & 17.78 & 0.97 \\
\hline & ACB15 & 0.664 & 2.708 & 0.99 & 6.679 & 0.362 & 0.98 & 0.634 & 22.36 & 0.99 \\
\hline & ACB30 & 2.125 & 10.621 & 0.99 & 67.627 & 0.164 & 0.99 & 1.729 & 26.59 & 0.94 \\
\hline \multirow{4}{*}{ 4-NP } & ACA15 & 0.126 & 1.892 & 0.99 & 4.923 & 0.175 & 0.99 & 0.109 & 9.76 & 0.96 \\
\hline & ACA30 & 0.194 & 0.716 & 0.99 & 1.068 & 0.453 & 0.97 & 0.133 & 22.35 & 0.90 \\
\hline & ACB15 & 1.331 & 17.110 & 0.99 & 51.728 & 0.252 & 0.93 & 1.193 & 17.78 & 0.96 \\
\hline & ACB30 & 2.568 & 100.641 & 0.99 & 134.96 & 0.148 & 0.99 & 2.104 & 19.88 & 0.94 \\
\hline \multirow{4}{*}{ 4-CP } & ACA15 & 0.598 & 2.116 & 0.98 & 13.290 & 0.244 & 0.99 & 0.439 & 21.14 & 0.90 \\
\hline & ACA30 & 0.648 & 1.422 & 0.98 & 6.980 & 0.367 & 0.99 & 0.585 & 17.78 & 0.95 \\
\hline & ACB15 & 1.944 & 12.860 & 0.98 & 75.339 & 0.198 & 0.90 & 1.869 & 22.44 & 0.93 \\
\hline & ACB30 & 3.888 & 10.288 & 0.99 & 161.09 & 0.171 & 0.94 & 4.273 & 26.59 & 0.92 \\
\hline
\end{tabular}

The $R_{L}$ values in this research are below 1 for the adsorption of phenolic compounds, showing that the adsorption is very favorable.

The Freundlich model has shown to be applied to adsorbents having energetically heterogeneous surfaces, $K_{f}$ has the highest values for sample ACB30 in adsorption of 4chlorophenol, which is directly related to the adsorption capacity of the sample, the $n$ parameter represents the intensity of the adsorption, and it appears in all values are less than 1 indicating that the favorability in the phenolic compounds adsorption on ACs $[4,11,13]$.

Data were also fitted to the Dubinin- RadusckevischKanager model, with similar trends to previous models. The parameters $n$ and $E_{s}$ are in principle responsible of surface heterogeneity for adsorbate-adsorbent system [14]. The $E_{s}$ parameter is related to the characteristic energy of 
TABLE 3: Thermodynamic parameters for the adsorption of phenols on ACs.

\begin{tabular}{|c|c|c|c|c|c|c|}
\hline Phenols & ACs & $-\Delta G^{\circ} 20^{\circ} \mathrm{C}\left(\mathrm{kJ} \mathrm{mol}^{-1}\right)$ & $-\Delta G^{\circ} 30^{\circ} \mathrm{C}\left(\mathrm{kJ} \mathrm{mol}^{-1}\right)$ & $-\Delta G^{\circ} 40^{\circ} \mathrm{C}\left(\mathrm{kJ} \mathrm{mol}^{-1}\right)$ & $-\Delta H^{\circ}\left(\mathrm{kJ} \mathrm{mol}{ }^{-1}\right)$ & $\Delta S^{\circ}\left(\mathrm{J} \mathrm{mol}^{-1}\right)$ \\
\hline \multirow{4}{*}{ Phenol } & CAA15 & 0.82 & 0.81 & 0.79 & 7.22 & 2.83 \\
\hline & CAA30 & 0.68 & 0.55 & 0.17 & 1.42 & -22.26 \\
\hline & CAB15 & 2.43 & 1.51 & 1.81 & 21,31 & 17.4 \\
\hline & CAB30 & 5.76 & 3.95 & 4.81 & 26.09 & 70.5 \\
\hline \multirow{4}{*}{ 4-NPl } & CAA15 & 1.55 & 1.95 & 1.75 & 4.52 & -10.23 \\
\hline & CAA30 & 0.81 & 1.22 & 0.63 & 1.35 & -11.91 \\
\hline & CAB15 & 2.68 & 4.91 & 4.04 & 17.82 & -71.58 \\
\hline & CAB30 & 5.62 & 3.67 & 4.19 & 25.96 & -32.08 \\
\hline \multirow{4}{*}{ 4-CP } & CAA15 & 1.83 & 1.79 & 2.35 & 5.74 & -25.52 \\
\hline & CAA30 & 1.64 & 1.94 & 0.96 & 0.95 & -7.22 \\
\hline & CAB15 & 2.93 & 4.23 & 4.37 & 18.32 & -73.11 \\
\hline & CAB30 & 5.68 & 3.53 & 3.79 & 30.8 & 97.27 \\
\hline
\end{tabular}

the process; it is indicative of the energy involved in the adsorption process to certain experimental conditions such as temperature, $\mathrm{pH}$, and ionic strength of the liquid-solid system under study. As seen in the results, the energy is higher in the ACB30 sample and it is related to its higher adsorption capacity compared to the other samples which, for this sample, were $26.59,19.88$, and $26.59 \mathrm{~kJ} \mathrm{~mol}^{-1}$ for phenol, 4-NP, and 4-CP, respectively; some values increased with the substitution in the aromatic ring, which causes a greater interaction with surface groups of carbon, but other sides are higher in the phenol because this energy is also related to the solubility of the compounds [17-21].

Data were better adjusted to Langmuir model for the linear correlation coefficient and found values between 0.97 and 0.99 and low values of percentage deviation not exceeding $1.2 \%$, meaning that the adsorbent has energetically heterogeneous surfaces.

3.3. Thermodynamic Analysis. The thermodynamic parameters of the system: Gibbs free energy change $\left(\Delta G^{\circ}\right)$, enthalpy change $\left(\Delta H^{\circ}\right)$, and entropy change $\left(\Delta S^{\circ}\right)$, are presented in Table 3; the free energy values at temperatures $20^{\circ} \mathrm{C}, 30^{\circ} \mathrm{C}$, and $40^{\circ} \mathrm{C}$ in adsorption of phenol, 4-NP, and 4-CP were negative in all cases showing the spontaneous nature of the process; it also shows that free energy values increase with the addition of nitro or chlorine groups to phenol. The maximum value of $\Delta G^{\circ}$ for adsorption at $20^{\circ} \mathrm{C}$ was in ACB30 for three phenols data directly related to the adsorption capacity of this carbon. The activated carbon that retains fewer amounts of phenolic compounds is ACA30, sample with fewer values in free energy also with values of $0.68,0.81$, and $1.64 \mathrm{~kJ} \mathrm{~mol}^{-1}$ for phenol, 4-NP, and 4-CP, respectively. In this study, the free energy values are in the range between -0.63 and $-5.76 \mathrm{~kJ} \mathrm{~mol}^{-1}$ indicating that the adsorption process occurs by physisorption [17-25].

$\Delta H^{\circ}$ values are negative for all of the phenols, showing the exothermic nature of the adsorption process; the maximum values for the three phenols were in ACB30 with values of $-26.09,-26.96$, and $-33.80 \mathrm{~kJ} \mathrm{~mol}^{-1}$ for phenol, 4-NP, and 4-CP, respectively, and the minimum value of
$\Delta H^{\circ}$ was in ACA30 for the adsorption of 4-chlorophenol with $0.96 \mathrm{~kJ} \mathrm{~mol}^{-1}$; however, adsorption of phenol and 4NP presents minimum values in ACA15 with values of 1.40 and $1.35 \mathrm{~kJ} \mathrm{~mol}^{-1}$, respectively; these enthalpy values are also related to the adsorption capacity of the samples. This enthalpies represents the interaction energy of the amount adsorbed on the absorbent-adsorbate interface. Enthalpy change values are between -0.95 and $-33.8 \mathrm{~kJ} \mathrm{~mol}^{-1}$; therefore, it follows a behavior of physisorption in the process [1727].

$\Delta S^{\circ}$ values were also reported; positive values suggest that the organization of the adsorbate in the solid-solution interface becomes more random, while a negative value indicates the opposite fact. Change of the $\Delta S^{\circ}$ value is linked to the movement of water molecules adsorbed by the adsorbate; it is observed that the higher values are for ACB30 and ACB15 on adsorption of 4-nitrophenol and 4-chlorophenol, respectively, with values of 71.58 to $97.27 \mathrm{~kJ} \mathrm{~mol}^{-1}$; therefore, it can be inferred that more water molecules are displaced by phenol derivatives with higher substitution degrees on the surface of these carbons.

Figure 5 shows the values of the enthalpy of adsorption of phenol, 4-NP, and 4-CP in relation to characteristic energy calculated from DRK model for all ACs, and this ratio has a behavior directly proportional because while increasing the value enthalpy the characteristic energy also increases, so that the energy characteristic and enthalpy reflected the interactions of the phenolic compounds with the carbonaceous solids. The smaller values points correspond to ACs with sulfuric acid and the points with high intensity represent the interactions of ACs with sodium hydroxide related aspect with adsorptive capacity and physicochemical properties. It can also be seen that higher $E_{S}$ values were for phenol and 4-chlorophenol compared with 4-nitrophenol; this was related to solubility of these compounds because the more soluble compounds have higher values of characteristic energy, while the less soluble compound as 4-nitrophenol has lower amount of characteristic energy and enthalpy in the interface.

Figures 6(a) and 6(b) show the correlation between the enthalpies of adsorption of phenol, 4-NP, and 4-CP with 


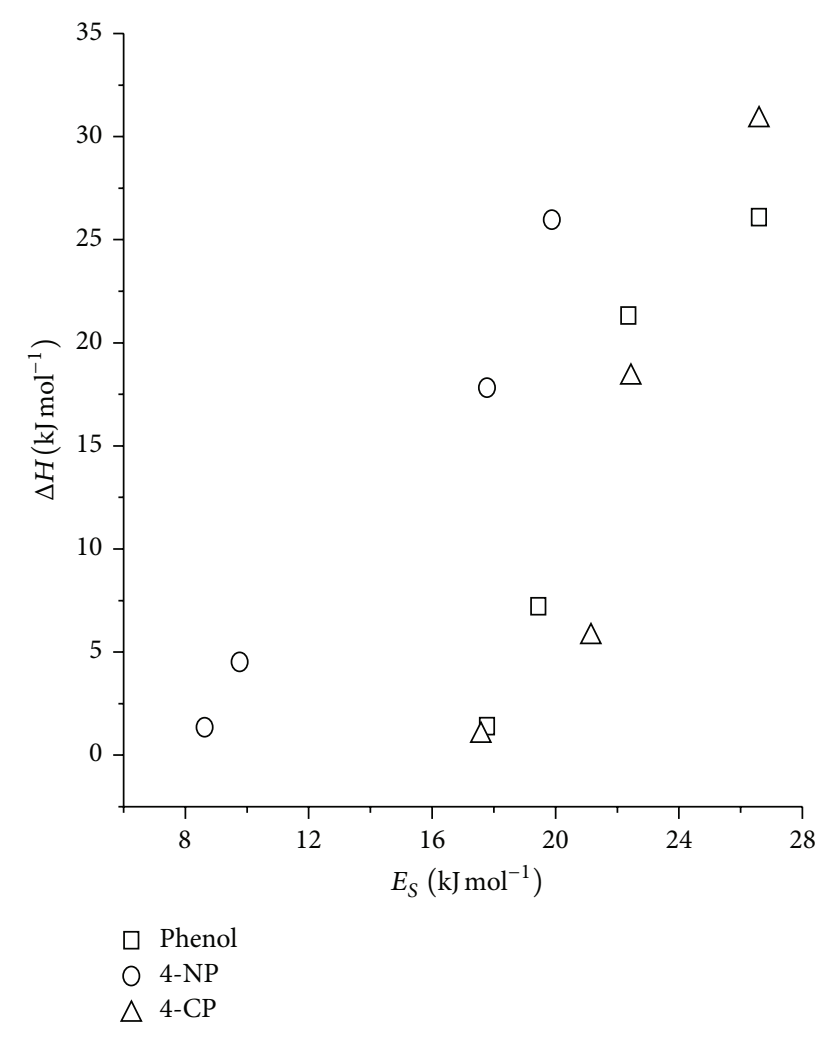

FIGURE 5: Correlation between enthalpies changes of adsorption and characteristics energies of phenols on ACs.

the amount adsorbed on monolayer from the DubininRadushkevich-Kanager and Langmuir models; this rise is directly proportional, where the adsorbed amount was greater and there were higher enthalpy values indicative of greater interaction of the solute with the activated carbon. The higher values for monolayer adsorbed amount and enthalpy change were on $\mathrm{ACB} 30$ and $\mathrm{ACB} 10$ and are present in the upper parts of the graph.

The adsorbed amount $\left(Q_{e}\right)$ relates to free energy change $(\Delta G)$ for each initial concentration as shown in Figure 7.

Smaller $\Delta G$ values for phenol adsorption occur on ACA30 (Figure $7(\mathrm{a})$ ) and these are between -400 and $-3600 \mathrm{~J} \mathrm{~mol}^{-1}$. When the system reduces the adsorbed amount becomes available for the adsorption process due to increasing the values of $\Delta G$. Figure 7(b) shows that higher $\Delta G$ values for phenol adsorption were on ACB30 with values between -4000 and $-18000 \mathrm{~J} \mathrm{~mol}^{-1}$, and the carbon with the maximum value of $\Delta G$ on adsorption of $4-\mathrm{NP}$ was ACB30 with values between -2300 and $-17000 \mathrm{~J} \mathrm{~mol}^{-1}$ but is larger in the 4 -chlorophenol with values up to $-210000 \mathrm{~J} \mathrm{~mol}^{-1}$. For adsorption of 4-NP and 4-CP values increase with decreasing amount of adsorption for all carbons compared with phenol, which makes the system more available for the adsorption process, aspect related to monolayer amount adsorbed by ACs for the two adsorbates $[38,39]$.

The equilibrium concentration sets a new thermodynamic state of the system which is reached when the interaction between the adsorbent and the phenolic compound is performed; therefore, energy free graphs were constructed, according to the equilibrium concentration of solutions of phenol, 4-nitrophenol, and 4-chlorophenol, at $20^{\circ} \mathrm{C}$, and these are presented in Figures 8(a) and 8(b) for the ACs.

In Figures 8(a) and 8(b) the free energy change decreases when increasing the equilibrium concentration of phenolic compounds on ACs, and such reduction is set to a logarithmic behavior [15]; it shows that equilibrium concentration values are close to phenol, that have a near relation with higher values of free energy on $\mathrm{ACB} 30$, intermediates values on ACB 15 and lowers on ACA15 and finally, for ACA30 this interaction is less. The adsorption capacity results are in agreement with the thermodynamic analysis and adjustments to the Langmuir, Freundlich and DRK models. For 4-NP and 4-CP behaviors were similar to phenol. However, higher free energy values on 4-CP adsorption were observed showing that there was more interaction and hence best adsorption capacity in relation to 4-NP for all carbons. These particular groups of thermodynamic result show that the adsorbent can be reusable, which gives an added value.

Finally, another important aspect to study the adsorption process is the $\mathrm{pH}$ of solution; it indicates the concentration of phenolic species present in solution. Therefore the content of phenolic compound are protonated at low $\mathrm{pH}$ and high $\mathrm{pH}$ high dissociated species predominate [19]. Experimental pH values for isotherms phenolic compounds in this study were between 6.1 and 8.2 to phenol, 5.4 and 7.1 to $4-\mathrm{NP}$, and 5.9 and 7.7 for 4-CP with this data and the curves calculated of the distribution of species is demonstrated that the process was performed by protonated species of phenol, and the process was favored by dispersion forces, and this was also tested with the $\mathrm{pK}_{\mathrm{a}}$ for the phenolic compound and the values are $9.89,7.15$, and 9.37 to phenol, $4-\mathrm{NP}$, and $4-\mathrm{CP}$, and in the same order, these values are higher compared with data reported in the literature studied $\mathrm{pH}$ for solutions which also indicates that the adsorbed species were in their protonated form $[18,21,26]$.

Figure 9 shows $\mathrm{pH}_{\mathrm{PZC}}$ of ACs in function of maximum adsorbed amount of phenol, 4-NP, and 4-CP obtained from Langmuir and DRK models, and the increasing value of $\mathrm{pH}_{\text {PZC }}$ also increases the monolayer adsorption capacity, with similar trend for two models. At low $\mathrm{pH}_{\mathrm{PZC}}$ the adsorption capacity decreases. At low pHPZC the adsorption capacity decreases, which was tested for for activated carbons treated (ACA30 and ACA15) those are at the bottom of the figure.

\section{Conclusions}

Activated carbons obtained from eucalyptus seed husk were characterized in physical/chemical properties and studied for the adsorption of phenol, 4-NP, and 4-CP under different temperatures. Adsorption of phenol compounds are produced in greater quantity on activated carbon samples activated with $\mathrm{NaOH}$, and not on the solids with more surface area. Therefore, the adsorption capacities $\left(\right.$ at $\left.20^{\circ} \mathrm{C}\right)$ on ACB30 for phenol, 4-NP, and 4-CP were 2.12, 2.57, and $3.89 \mathrm{mmol} \mathrm{g}^{-1}$, respectively. There is great correlation in the Langmuir and DRK models in the amount adsorbed monolayer. However, 


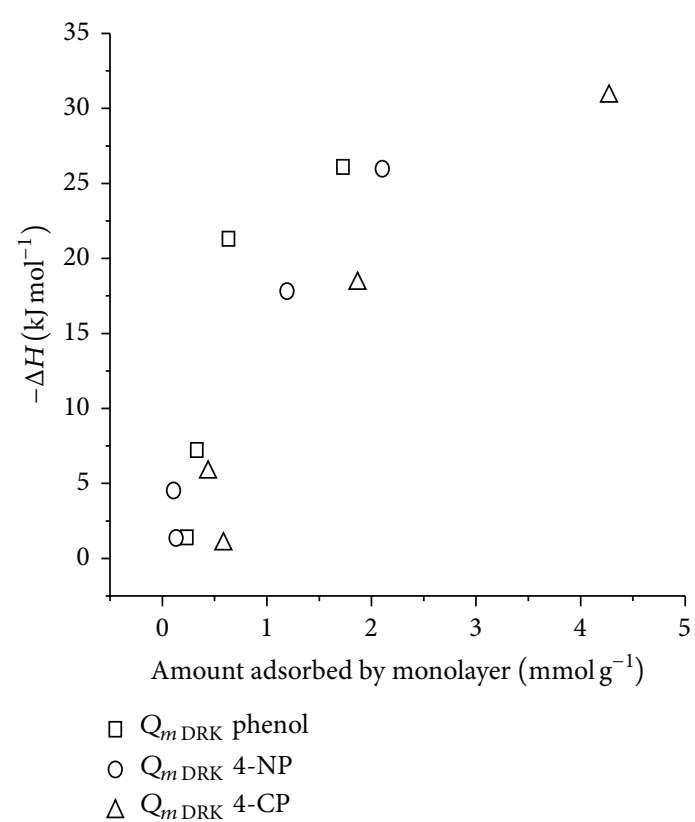

(a)

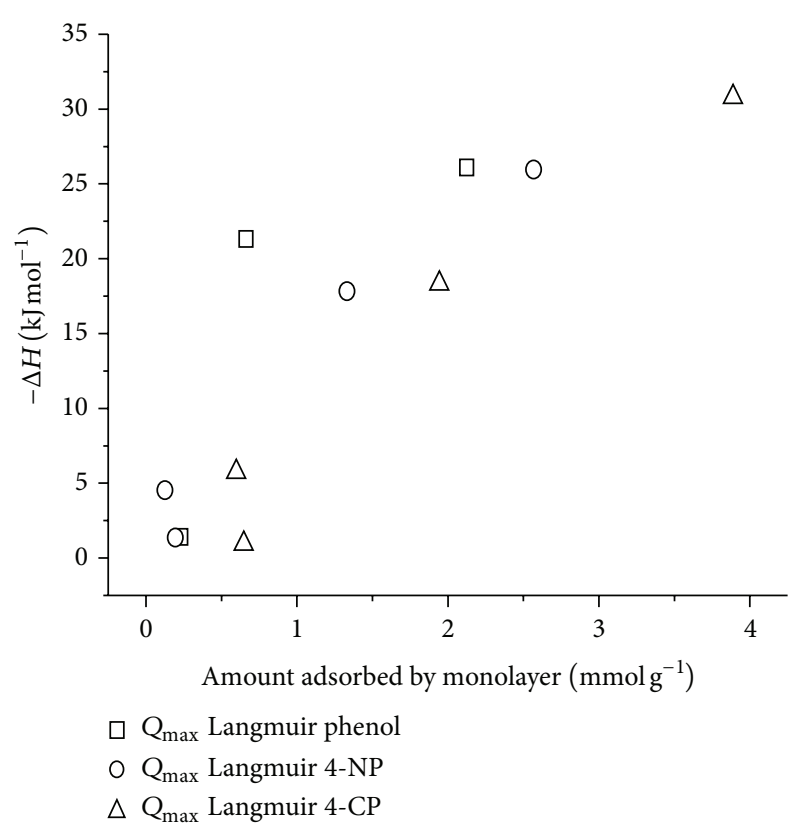

(b)

FIGURE 6: Correlation between the enthalpies changes of adsorption and amount adsorbed by monolayer of phenolson ACs.

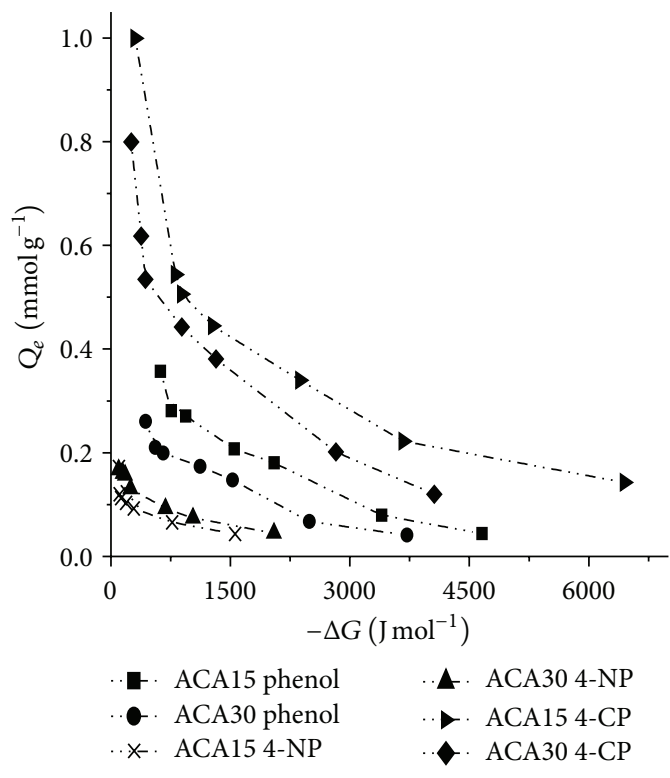

(a)

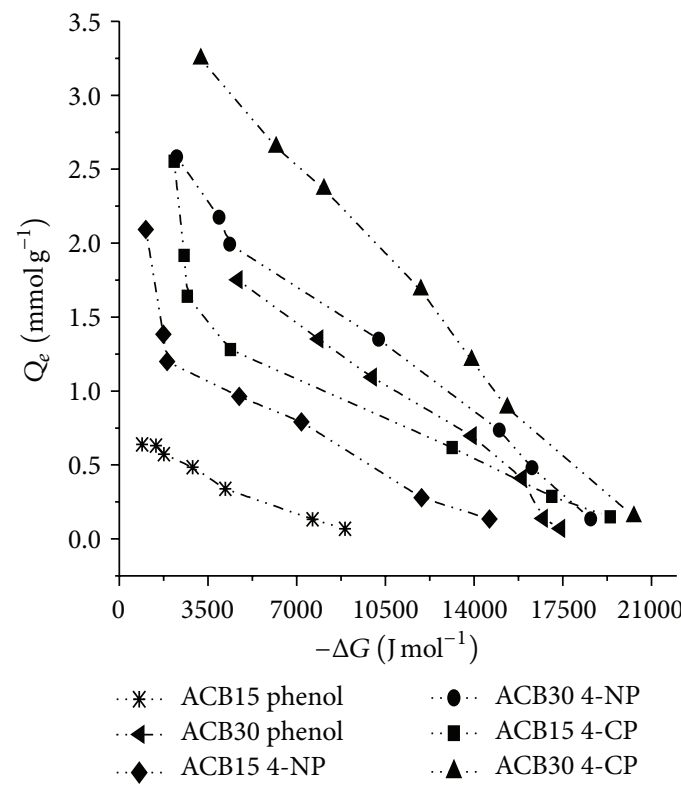

(b)

FIGURE 7: Adsorbed amount of phenols in function of the change in free energy on ACs at $20^{\circ} \mathrm{C}$.

Langmuir model gives the best fitting for the adsorption isotherm in most cases.

Adsorption of phenols compounds decreases with increasing temperature, so it checks the exothermic nature of the adsorption process. Free energy values for all temperatures for adsorption of the three phenols compounds were negative in all cases, showing the spontaneous nature of the adsorption process, and $\Delta H^{\circ}$ values were negative for all phenols, showing the exothermic nature of the adsorption process and increased entropy change with the increase of substitution degree. Based on thermodynamic parameters, the adsorption is primarily physical in nature.

Finally, the uptakes were observed at $\mathrm{pH}<\mathrm{pK}_{\mathrm{a}}$ which indicates that the adsorbed phenols species were in their protonated form which improves the adsorption process on ACs. 


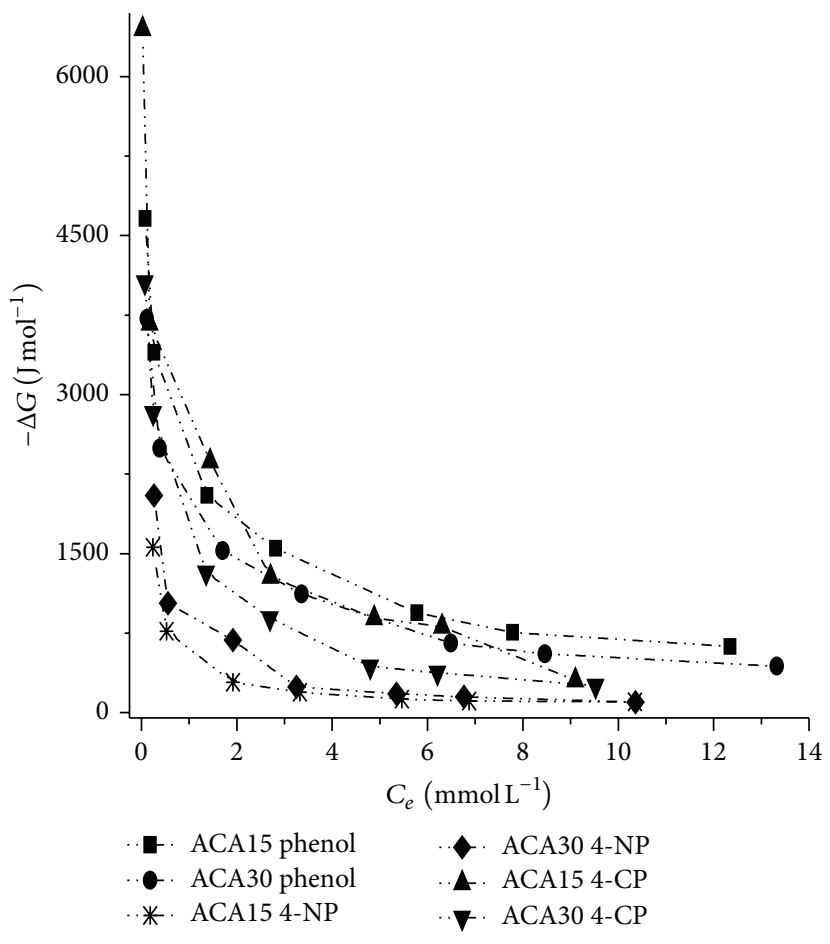

(a)

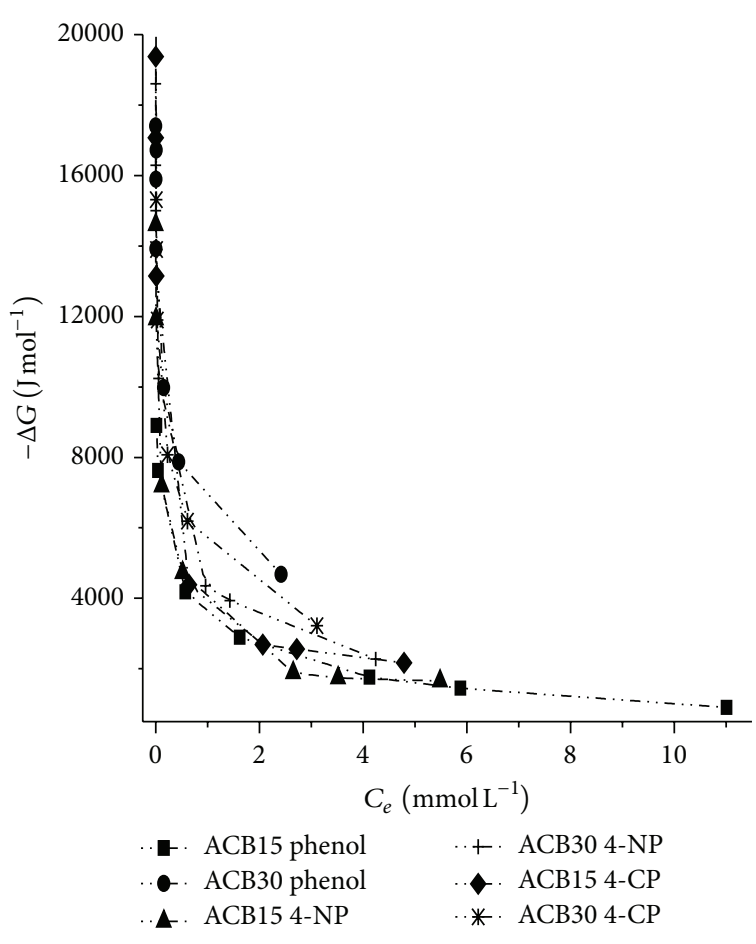

(b)

FIGURE 8: Change in free energy in function of equilibrium concentration of phenols on ACs at $20^{\circ} \mathrm{C}$.

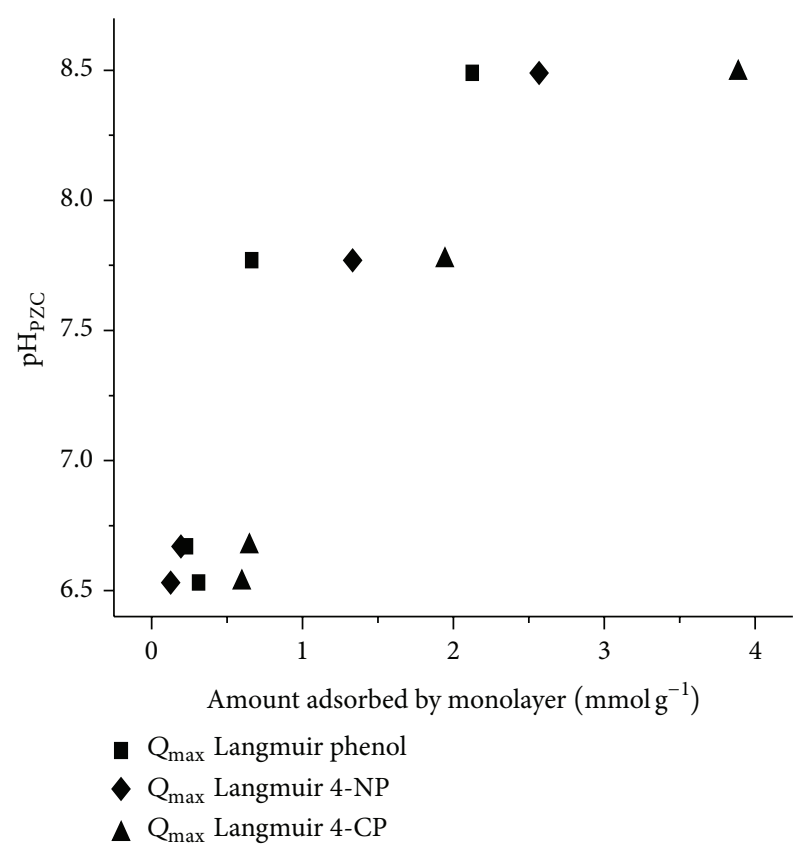

(a)

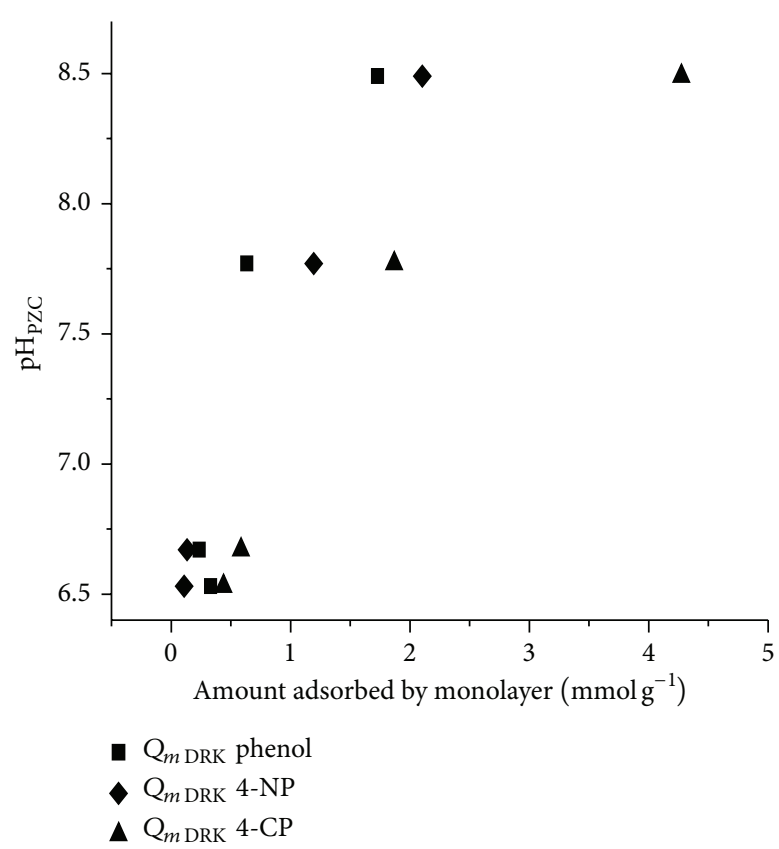

(b)

FIGURE 9: Correlation between $\mathrm{pH}_{\mathrm{PZC}}$ and maximum amount adsorbed of phenols on ACs. 


\section{Conflict of Interests}

The authors declare that there is no conflict of interests regarding the publication of this paper.

\section{Acknowledgments}

The authors wish to thank the Master Agreement established between the "Universidad de los Andes" and the "Universidad Nacional de Colombia" and the Memorandum of Understanding entered into by the Departments of Chemistry of both universities. Additionally, the authors are also thankful for financial support by the program Jovenes Investigadores e Innovadores, "Virginia Gutiérrez de Pineda," by resolution no. 664 Rag: 664/2013-2063.

\section{References}

[1] N. M. Nor, L. C. Lau, K. T. Lee, and A. R. Mohamed, "Synthesis of activated carbon from lignocellulosic biomass and its applications in air pollution control-a review," Journal of Environmental Chemical Engineering, vol. 1, no. 4, pp. 658-666, 2013.

[2] B. Cagnon, X. Py, A. Guillot, F. Stoeckli, and G. Chambat, "Contributions of hemicellulose, cellulose and lignin to the mass and the porous properties of chars and steam activated carbons from various lignocellulosic precursors," Bioresource Technology, vol. 100, no. 1, pp. 292-298, 2009.

[3] P. J. M. Suhas, M. M. L. Carrott, and R. Carrott, "Lignin-from natural adsorbent to activated carbon: a review," Bioresource Technology, vol. 98, no. 12, pp. 2301-2312, 2007.

[4] O. Ioannidou and A. Zabaniotou, "Agricultural residues as precursors for activated carbon production-a review," Renewable and Sustainable Energy Reviews, vol. 11, no. 9, pp. 1966-2005, 2007.

[5] A. Demirbas, "Adsorption of lead and cadmium ions in aqueous solutions onto modified lignin from alkali glycerol delignication," Journal of Hazardous Materials, vol. 109, no. 1-3, pp. 221226, 2004.

[6] S. J. Allen, B. Koumanova, Z. Kircheva, and S. Nenkova, "Adsorption of 2-nitrophenol by technical hydrolysis lignin: kinetics, mass transfer, and equilibrium studies," Industrial and Engineering Chemistry Research, vol. 44, no. 7, pp. 2281-2287, 2005.

[7] T. C. Chandra, M. M. Mirna, Y. Sudaryanto, and S. Ismadji, "Adsorption of basic dye onto activated carbon prepared from durian shell: studies of adsorption equilibrium and kinetics," Chemical Engineering Journal, vol. 127, no. 1-3, pp. 121-129, 2007.

[8] T. C. Chandra, M. M. Mirna, J. Sunarso, Y. Sudaryanto, and S. Ismadji, "Activated carbon from durian shell: preparation and characterization," Journal of the Taiwan Institute of Chemical Engineers, vol. 40, no. 4, pp. 457-462, 2009.

[9] K. Nuithitikul, S. Srikhun, and S. Hirunpraditkoon, "Influences of pyrolysis condition and acid treatment on properties of durian peel-based activated carbon," Bioresource Technology, vol. 101, no. 1, pp. 426-429, 2010.

[10] Y. J. Tham, P. A. Latif, A. M. Abdullah, A. Shamala-Devi, and Y. H. Taufiq-Yap, "Performances of toluene removal by activated carbon derived from durian shell," Bioresource Technology, vol. 102, no. 2, pp. 724-728, 2011.
[11] W. Li, K. Yang, J. Peng, L. Zhang, S. Guo, and H. Xia, "Effects of carbonization temperatures on characteristics of porosity in coconut shell chars and activated carbons derived from carbonized coconut shell chars," Industrial Crops and Products, vol. 28, no. 2, pp. 190-198, 2008.

[12] W. Li, J. Peng, L. Zhang et al., "Preparation of activated carbon from coconut shell chars in pilot-scale microwave heating equipment at $60 \mathrm{~kW}$,' Waste Management, vol. 29, no. 2, pp. 756$760,2009$.

[13] K. Sun and J. C. Jiang, "Preparation and characterization of activated carbon from rubber-seed shell by physical activation with steam," Biomass and Bioenergy, vol. 34, no. 4, pp. 539-544, 2010.

[14] E. Şayan, "Ultrasound-assisted preparation of activated carbon from alkaline impregnated hazelnut shell: an optimization study on removal of $\mathrm{Cu}^{2+}$ from aqueous solution," Chemical Engineering Journal, vol. 115, no. 3, pp. 213-218, 2006.

[15] D. D. Milenković, P. V. Dašić, and V. B. Veljković, "Ultrasoundassisted adsorption of copper(II) ions on hazelnut shell activated carbon," Ultrasonics Sonochemistry, vol. 16, no. 4, pp. 557$563,2009$.

[16] M. Kobya, "Removal of $\mathrm{Cr}(\mathrm{VI})$ from aqueous solutions by adsorption onto hazelnut shell activated carbon: kinetic and equilibrium studies," Bioresource Technology, vol. 91, no. 3, pp. 317-321, 2004.

[17] Q.-S. Liu, T. Zheng, P. Wang, J.-P. Jiang, and N. Li, "Adsorption isotherm, kinetic and mechanism studies of some substituted phenols on activated carbon fibers," Chemical Engineering Journal, vol. 157, no. 2-3, pp. 348-356, 2010.

[18] M. Ahmaruzzaman and D. K. Sharma, "Adsorption of phenols from wastewater," Journal of Colloid and Interface Science, vol. 287, no. 1, pp. 14-24, 2005.

[19] A. Kumar, S. Kumar, and D. V. Gupta, "Adsorption of phenol and 4-nitrophenol on granular activated carbon in basal salt medium: equilibrium and kinetics," Journal of Hazardous Materials, vol. 147, no. 1-2, pp. 155-166, 2007.

[20] K. P. Singh, A. Malik, S. Sinha, and P. Ojha, "Liquid-phase adsorption of phenols using activated carbons derived from agricultural waste material," Journal of Hazardous Materials, vol. 150, no. 3, pp. 626-641, 2008.

[21] F. Rodriguez Reinoso, "El Carbón Activado como Adsorbente Universal," in Sólidos Porosos: preparación, Caracterización y Aplicaciones Bogotá, J. Moreno Pirajan, Ed., Ediciones Uniandes, Bogotá, Colombia, 2007.

[22] M. Olivares-Marín, C. Fernández-González, A. Macías-García, and V. Gómez-Serrano, "Preparation of activated carbon from cherry stones by physical activation in air. Influence of the chemical carbonisation with $\mathrm{H}_{2} \mathrm{SO}_{4}$," Journal of Analytical and Applied Pyrolysis, vol. 94, pp. 131-137, 2012.

[23] X. Deglise and P. Magne, "Pyrolysis and industrial charcoal," in Biomass : Regenerable Energy, D. O. Hall and R. P. Overend, Eds., p. 221, John Wiley \& Sons, London, UK, 1987.

[24] J. Pastor-Villegas, V. Gómez-Serrano, C. J. Durán-Valle, and F. J. Higes-Rolando, "Chemical study of extracted rockrose and of chars and activated carbons prepared at different temperatures," Journal of Analytical and Applied Pyrolysis, vol. 50, no. 1, pp. 116, 1999.

[25] F. A. Cotton and S. G. Wilkinson, Advanced Inorganic Chemistry :A Comprehensive Text, Interscience Publishers, New York, NY, USA, 3rd edition, 1962-1972.

[26] J. F. González, J. M. Encinar, J. L. Canito, E. Sabio, and M. Chacón, "Pyrolysis of cherry stones: energy uses of the different 
fractions and kinetic study," Journal of Analytical and Applied Pyrolysis, vol. 67, no. 1, pp. 165-190, 2003.

[27] E. Iniesta, F. Sánchez, A. N. García, and A. Marcilla, "Yields and $\mathrm{CO}_{2}$ reactivity of chars from almond shells obtained by a two heating step carbonisation process. Effect of different chemical pre-treatments and ash content," Journal of Analytical and Applied Pyrolysis, vol. 58-59, pp. 983-994, 2001.

[28] P. Álvarez, C. Blanco, R. Santamaría, and M. Granda, "Improvement of the thermal stability of lignocellulosic materials by treatment with sulphuric acid and potassium hydroxide," Journal of Analytical and Applied Pyrolysis, vol. 72, no. 1, pp. 131-139, 2004.

[29] J. A. Caballero, A. Marcilla, and J. A. Conesa, "Thermogravimetric analysis of olive stones with sulphuric acid treatment," Journal of Analytical and Applied Pyrolysis, vol. 44, no. 1, pp. 7588, 1997.

[30] J. Martín Martínez, "Generalidades sobre adsorción física de gases y vapores en carbones," in Adsorción Física de Gases y Vapores por Carbones, J. Martín Martínez, Ed., Secretariado de Publicaciones de la Universidad de Alicante, Alicante, Spain, 1990.

[31] R. Lovera-García, "Caracterización textural de adsorbentes," Revista Chilena de Ingeniería, vol. 28, no. 6, pp. 24-28, 2003.

[32] H. P. Boehm, "Some aspects of the surface chemistry of carbon blacks and other carbons," Carbon, vol. 32, no. 5, pp. 759-769, 1994.

[33] M. V. Lopez-Ramon, F. Stoeckli, C. Moreno-Castilla, and F. Carrasco-Marin, "On the characterization of acidic and basic surface sites on carbons by various techniques," Carbon, vol. 37, no. 8, pp. 1215-1221, 1999.

[34] L. C. Mojica-Sanchez, W. M. Ramirez-Gomez, N. G. RinconSilva, D. A. Blanco-Martinez, L. Giraldo, and J. C. MorenoPirajan, "Synthesis of activated carbon from Eucalyptus seed physical and chemical activation," Afinidad, vol. 69, no. 559, 2012.

[35] R.-L. Tseng, K.-T. Wu, F.-C. Wu, and R.-S. Juang, "Kinetic studies on the adsorption of phenol, 4-chlorophenol, and 2,4dichlorophenol from water using activated carbons," Journal of Environmental Management, vol. 91, no. 11, pp. 2208-2214, 2010.

[36] F. Rodríguez-Reinoso and A. Linares-Solano, Chemistry and Physics of carbon, vol. 21 of edited by Peter A. Thrower, CRC Press, New York, NY, USA, 1989.

[37] C. Moreno-Castilla, "Adsorption of organic molecules from aqueous solutions on carbon materials," Carbon, vol. 42, no. 1 , pp. 83-94, 2004.

[38] F. Stoeckli, A. Guillot, and A. M. Slasli, "Specific and nonspecific interactions between ammonia and activated carbons," Carbon, vol. 42, no. 8-9, pp. 1619-1624, 2004.

[39] H. F. Stoeckli and F. Kraehenbuehl, "The enthalpies of immersion of active carbons, in relation to the Dubinin theory for the volume filling of micropores," Carbon, vol. 19, no. 5, pp. 353-356, 1981. 

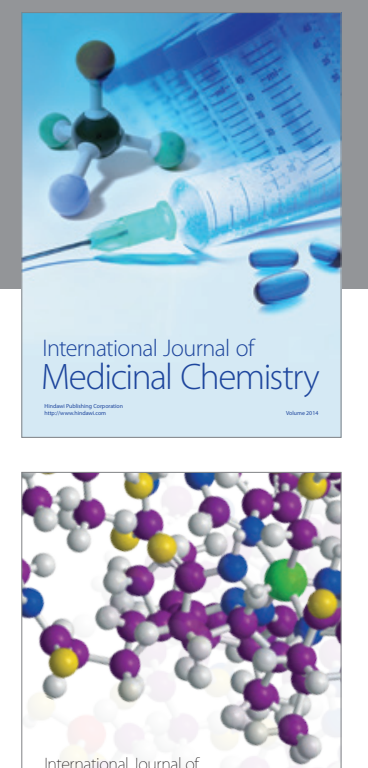

\section{Carbohydrate} Chemistry

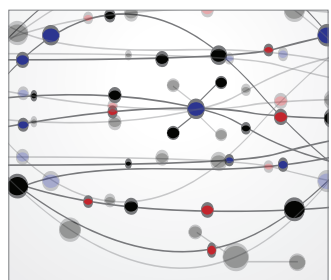

The Scientific World Journal
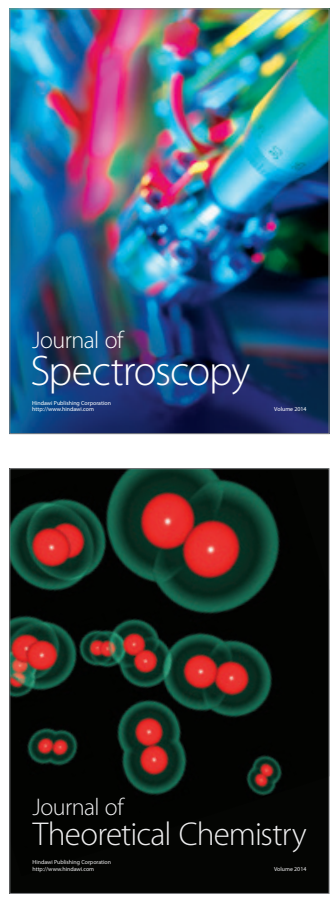
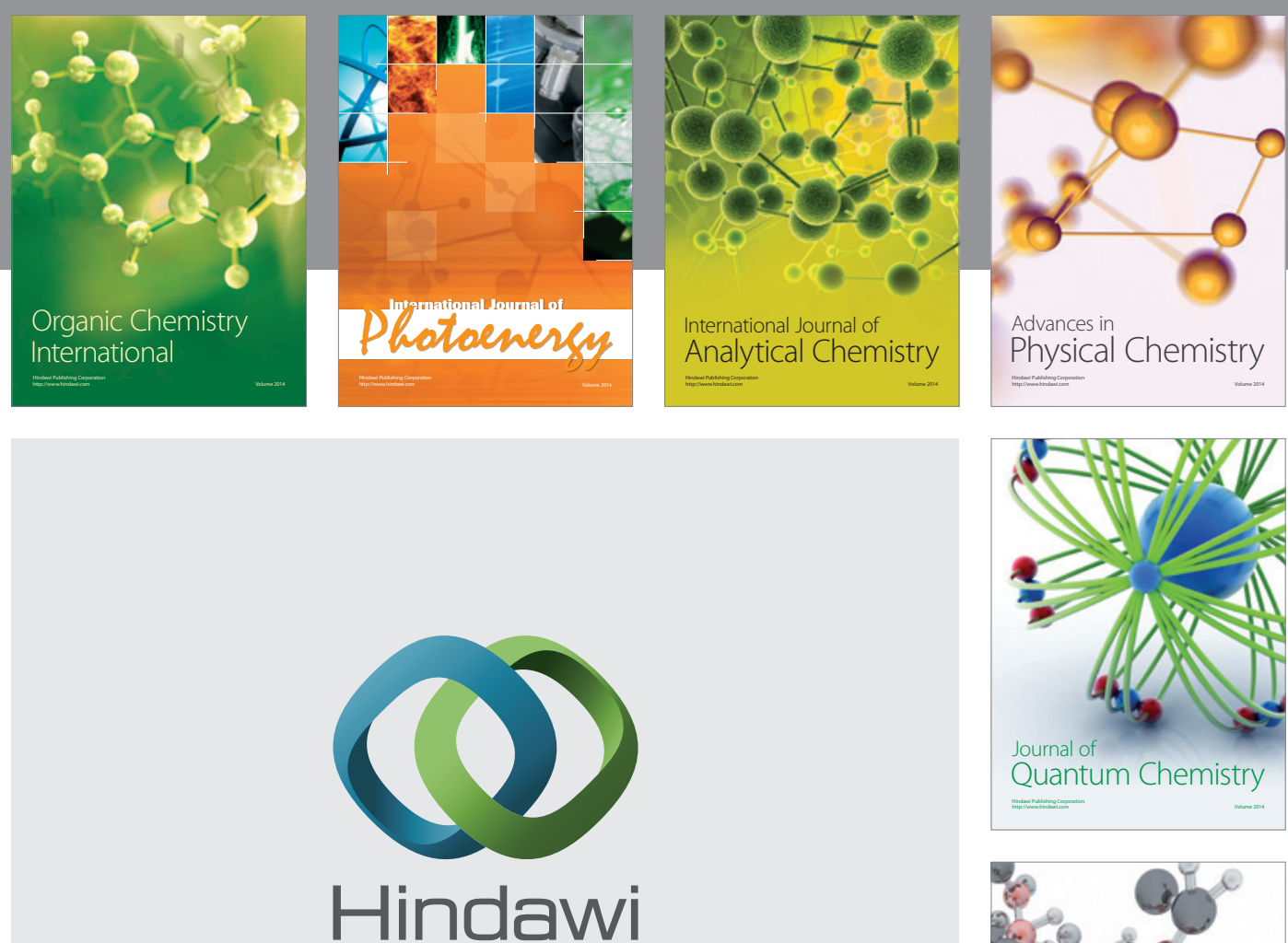

Submit your manuscripts at

http://www.hindawi.com

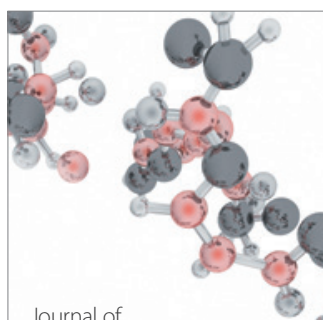

Analytical Methods

in Chemistry

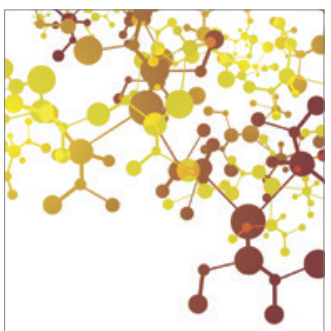

Journal of

Applied Chemistry

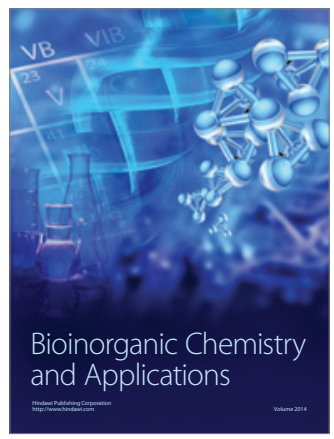

Inorganic Chemistry
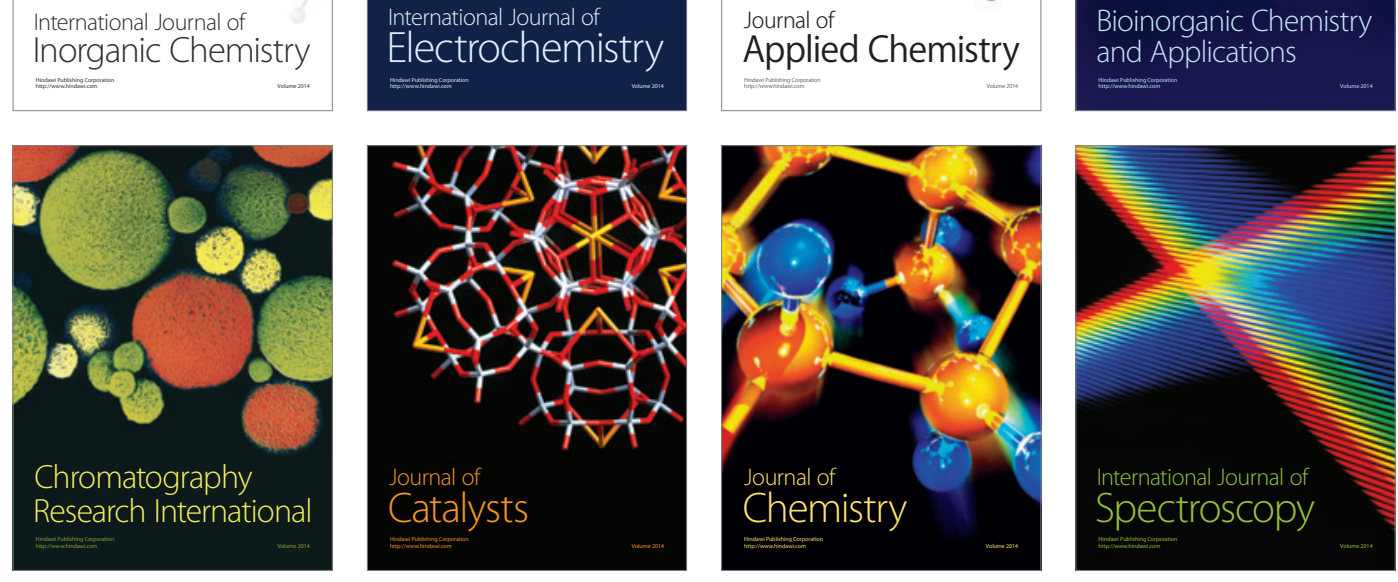